\title{
Study of the Thermochemical Properties of Ethanol Lignins from Abies and Aspen Wood
}

\author{
Nadezhda M. Mikova ${ }^{a}$, Olga Yu. Fetisova ${ }^{a}$, \\ Elena V. Mazurova ${ }^{a}$, Natalia M. Ivanchenkoa, \\ Maxim A. Lutoschkina, Laurent Djakovitch ${ }^{\mathrm{b}}$, \\ Nikolai V., Chesnokov a and Boris N. Kuznetsov*a \\ anstitute of Chemistry and Chemical Technology SB RAS \\ FRC "Krasnoyarsk Science Center SB RAS" \\ 50/24 Akademgorodok, Krasnoyarsk, 660036, Russia \\ ${ }^{b}$ IRCELYON
} 2 avenue Albert Einstein, F-69626 Villeurbanne Cedex, Lyon, France

Received 26.04.2018, received in revised form 14.06.2018, accepted 17.07.2018

The functional composition and thermochemical properties of the lignins isolated by ethanol extraction of fir and aspen wood were studied by the non-isothermal thermogravimetric analysis, FTIR spectroscopy, elemental analysis, and scanning electron microscopy. The peculiarities of thermal destruction of these two Types of lignin in inert (argon) and oxidizing (air) media were revealed. The maximum rates of decomposition of ethanol lignins from fir and aspen wood in an inert medium are reached at 400 and $377.6^{\circ} \mathrm{C}$, respectively. The thermal degradation of aspen lignin in air medium is accompanied by the appearance of two maxima at 275 and $355{ }^{\circ} \mathrm{C}$, and of fir lignin-one maximum at $402{ }^{\circ} \mathrm{C}$. The comparison of thermochemical properties of aspen wood and isolated from wood the ethanol lignin and cellulose was made. It was shown that the temperatures corresponding to the highest rates of thermal decomposition of aspen wood, cellulose and lignin in an inert medium are 363.4, 333.7 and $377.6^{\circ} \mathrm{C}$, respectively. In all temperature range, the thermal decomposition of aspen lignin, both in the inert and air medium proceeded at the higher rates of mass loss than that of fir lignin.

Keywords: ethanol lignin of fir and aspen, thermochemical properties, argon and air medium.

Citation: Mikova N.M., Fetisova O.Yu., Mazurova E.V., Ivanchenko N.M., Lutoschkin M.A., Djakovitch L., Chesnokov N.V., Kuznetsov B.N. Study of the thermochemical properties of ethanol lignins from abies and aspen wood, J. Sib. Fed. Univ. Chem., 2018, 11(3), 401-417. DOI: 10.17516/1998-2836-0086.

(C) Siberian Federal University. All rights reserved

* Corresponding author E-mail address: nm@icct.ru 


\title{
Изучение термохимических свойств
}

\section{ЭТаноЛЛигнинов Пихты и осины}

\author{
Н.М. Микова ${ }^{a}$, О.Ю. Фетисова ${ }^{a}$, \\ Е.В. Мазурова ${ }^{a}$ Н.М. Иванченко \\ Л. Дьякович ${ }^{0}$, Н.В. Чесноков ${ }^{a}$, Б.Н. Кузнецов ${ }^{a}$ \\ ${ }^{a}$ Институт химии и химической технологии СО РАН \\ ФИЦ «Красноярский научный центтр СО РАН» \\ Россия, 660036, Красноярск, Академгородок, 50/24 \\ ${ }^{6} I R C E L Y O N$ \\ 2 avenue Albert Einstein, F-69626 Villeurbanne Cedex, Lyon, France
}

Методами неизотермического термогравиметрического анализа, ИК-Фурье-спектроскопии, элементного анализа, сканирующей электронной микроскопии изучен функииональный состав и термохимические свойства лигнинов, выделенных экстракиией этанолом древесины пихты и осины. Выявлены особенности термодеструкиии этих двух видов лигнина в инертной (аргон) и окислительной (воздух) средах. Максимумы скорости разложения лигнинов пихты и осины в инертной среде достигаются при 400 и 377,6 ${ }^{\circ} \mathrm{C}$ соответственно. В воздушной среде термодеструкция лигнина осины сопровождается появлением двух максимумов при 275 и $355^{\circ} \mathrm{C}$, алигнина пихты - одного максимума при $402{ }^{\circ} \mathrm{C}$. Проведено сравнение термохимических свойств древесины осины и выделенных из нее этаноллигнина и целлюлозы. Показано, что температуры, соответствующие наибольшим скоростям терморазложения древесины осины, целлюлозы и лигнина в инертной среде, равны 363,4, 333,7 и 377,6 ${ }^{\circ} \mathrm{C}$ соответственно. Во всех температурных интервалах терморазложение лигнина осины как в инертной, так и в воздушной среде протекало с более высокими скоростями убыли массы, чем лигнина пихты.

Ключевые слова: этаноллигнин пихты и осины, термохимические свойства, среда аргона и воздуха.

\section{Введение}

В настоящее время различные аспекты термохимической конверсии биомассы, в частности лигнина, в жидкие топлива и ценные химические продукты являются предметом интенсивных исследований [1-4]. Для лучшего понимания сложного процесса пиролиза лигноцеллюлозной биомассы исследуются термохимические свойства ее основных компонентов - целлюлозы и лигнина. Результаты исследования пиролитического поведения лигнинов, выделенных из различных видов лигноцеллюлозной биомассы, имеют ограниченное значение для понимания механизма его термохимических превращений ввиду сложности их структуры и состава [5-7]. Изучение термохимических превращений индивидуальных соединений, моделирующих структурные фрагменты лигнина, позволяет получить дополнительные сведения о термодеструкции химических связей в лигнинах $[8,9]$. Были предложены серии реакций, описывающих распад различных фрагментов структуры лигнина и вероятные пути образования наиболее типичных 
продуктов пиролиза $[10,11]$. Но поскольку структура лигнина сложна и специфична для различных видов лигноцеллюлозной биомассы, результаты исследования термопревращений модельных соединений имеют ограниченное значение для понимания механизма пиролиза лигнина.

Традиционные методы выделения лигнинов из лигноцеллюлозной биомассы не обеспечивают полного сохранения его исходной структуры. Одним из распространенных способов выделения лигнина является экстракция биомассы органическими растворителями [12-14]. Полученные при этом органосольвентные лигнины (например, этаноллигнин) в меньшей степени отличаются от нативного лигнина по сравнению с техническими лигнинами, образующимися в промышленных процессах делигнификации и гидролиза древесины [15].

Методы термогравиметрического и спектральных анализов широко используются при изучении термохимической трансформации лигнинов и характеристики продуктов их разложения [16-18].

Целью данной работы стало исследование теромохимических свойств двух видов этаноллигнинов, выделенных из древесины типичных для Сибири хвойных и лиственных деревьевпихты (Abies sibirica) и осины (Populus tremula). Лигнин пихты сформирован фенилпропановыми фрагментами гваяцильного типа, а в лигнине осины преобладают структуры сирингильного типа. Были изучены термические превращения этих лигнинов в инертной и воздушной средах, сопоставлены состав и свойства продуктов их термодеструкции.

\section{Экспериментальная часть}

Термогравиметрическое изучение (ТГ-ДТГ) образцов лигнина, древесины и целлюлозы осины выполнено на приборе «Netzsch STA 449F1» (Германия) в воздушной среде и атмосфере аргона. Скорость нагрева образца (5 мг) от комнатной температуры до $800{ }^{\circ} \mathrm{C}$ составила $10{ }^{\circ} \mathrm{C} /$ мин. Обработка результатов измерений произведена с помощью прилагаемого пакета программ «Proteus Thermal Analysis. Version 5.1.0».

Термообработку образцов лигнина проводили в корундовом тигле, который помещали в трубчатую электрическую печь. Нагрев осуществляли со скоростью подъема температуры $10{ }^{\circ} \mathrm{C} /$ мин от комнатной до заданной $\left(200-600{ }^{\circ} \mathrm{C}\right)$ с выдержкой при конечной температуре 10 мин.

Элементный анализ C, H, N выполняли на анализаторе FlashEA ${ }^{\mathrm{TM}}-1112$ (Thermo Quest, Италия).

Морфологические исследования поверхности методом сканирующей электронной микроскопии (СЭМ) и микрорентгеноспектральный анализ (РСА) химического состава образцов проведены на сканирующем электронном микроскопе ТM-3000 Hitachi (Япония).

Регистрацию ИК-спектров поглощения в области 400-4000 см$^{-1}$ осуществляли на ИКФурье-спектрометре Tensor 27 (Brucker, Германия) Красноярского центра коллективного пользования. Твердые образцы (5 мг) для анализа готовили прессованием в виде таблеток в матрице $\mathrm{KBr}$. Обработку спектральной информации проводили с применением пакета программ OPUS, версия 5.0

Сорбционную способность по отношению к парам бензола, оцененную в значениях количества поглощенного бензола на единицу массы сухого образца (г/г), изучали в условиях стационарного равновесного заполнения пор при комнатной температуре.

$$
-403-
$$


В экспериментах использовали измельченные до фракции $\leq 0,10$ мм образцы этаноллигнина пихты (ЭЛП) и этаноллигнина осины (ЭЛО), полученные органосольветным способом по известной методике [14].

\section{Результаты и их обсуждение}

\section{Элементный состав этаноллигнинов}

Элементный состав ЭЛП, \% мас: С - 66,34; Н - 5,94; $\mathrm{O}_{\text {dif }}-27,54$ (на а.с.в). Элементный состав ЭЛО, \% мас: С - 63,90; Н - 6,61; $\mathrm{O}_{\mathrm{dif}}-29,40$ (содержание кислорода рассчитано по разнице). Средняя молекулярная масса образцов ЭЛО и ЭЛП, определенная методом гель-проникающей хроматографии на приборе Agilent 1260, составила соответственно для этаноллигнина осины 2724 г/моль, а для этаноллигнина пихты - 1740 г/моль.

Полученные этаноллигнины имеют различающуюся среднюю молекулярную массу, но близкий элементный состав, причем этаноллигнин осины имеет несколько меньшее содержание углерода и выше - кислорода, что служит следствием повышенного содержания метоксильных групп в лигнине лиственных пород по сравнению с хвойными. Содержание азота и зольности было минимальным ( $\leq 0,01 \%$ ), поэтому не принималось во внимание при расчете элементного состава лигнинов.

Наблюдаются некоторые расхождения в элементном составе этаноллигнинов от состава описанных в литературе уксуснокислотных лигнинов этих же пород деревьев [20]. Вероятной причиной этого является повышенное содержание кислородсодержащих функциональных групп, в частности карбоксильных, в составе уксуснокислотных лигнинов, полученных окислительной делигнификацией древесины пероксидом водорода в среде уксусная кислота-вода [19].

Отличия в составе хвойных и лиственных этаноллигнинов могут быть объяснены остаточным содержанием в лигнине других компонентов древесины, поскольку известно, что лигнин ковалентно связан с ксиланами в лиственных породах и с галактоглукоманнами в хвойных [20].

\section{ИК-спектроскопическое изучение этаноллигнинов}

Для сравнения структурных различий этаноллигнинов из осины и пихты были сопоставлены их ИК-Фурье-спектры в области 500-4000 $\mathrm{cm}^{-1}$. В спектрах образцов присутствуют характерные полосы поглощения (п.п.) основных видов функциональных групп (алифатические, карбонильные, гидроксильные, алкил- и арилэфирные) и С-С-связей, типичных для фенилпропановых структурных единиц лигнина [21].

В табл. 1 приведены результаты анализа основных полос поглощений, отвечающих наиболее характерным колебаниям функциональных групп в ИК-спектрах изученных видов лигнинов - хвойного (G-тип) и лиственного (S+G-тип).

В ИК-спектре этаноллигнина пихты (G-тип) наблюдаются характерные для лигнина хвойных пород полосы поглощения в области 1600-800 см-1, интенсивности которых изменяются в следующем порядке: $1600<<1514$ (максимально) $>>1463 \mathrm{~cm}^{-1} ; 1270$ (очень сильная) $>>1214>$ $>1143 \sim 1033 \mathrm{~cm}^{-1}$. В спектре лигнина осины (S+G-тип) интенсивности п.п. изменяются следующим образом: $1594 \geq 1515 \approx 1463 \mathrm{~cm}^{-1} ; 1328>1270<1218<<1121$ (очень сильная) $>1033 \mathrm{~cm}^{-1}$.

$$
-404-
$$


Таблица 1. Основные полосы поглощения в ИК-спектрах этаноллигнинов и виды связей, им соответствующие

Table 1. The main absorption bands in the IR spectra of ethanollignins and the types of corresponding to them bonds

\begin{tabular}{|c|c|c|c|}
\hline \multicolumn{2}{|c|}{ Основные полосы поглощения, см$^{-1}$} & \multirow{2}{*}{ Тип связей } & \multirow{2}{*}{ Виды колебаний } \\
\hline ЭЛП (G-тип) & ЭЛО $(\mathrm{S} \geq \mathrm{G})$ & & \\
\hline $3423 \mathrm{c}$. & $3444 \mathrm{c}$. & $v \mathrm{OH}$ & фенольные, спиртовые \\
\hline $2936-2840 \mathrm{cp}$. & $2937-2842 \mathrm{cp}$. & $v \mathrm{C}-\mathrm{H}$ & алифатич. $-\mathrm{CH}_{3},-\mathrm{CH}_{2},-\mathrm{C}-\mathrm{H}$ \\
\hline $1706 \mathrm{cp}$ & $1712 \mathrm{cp}$. & $v \mathrm{C}=\mathrm{O}$ & $\begin{array}{l}\text { несопряженные } \\
\text { карбонильные }\end{array}$ \\
\hline $\begin{array}{c}1600 \text { ср.; } 1514 \text { оч. с.; } \\
1427 \text { сp. }\end{array}$ & $\begin{array}{l}1594 \text { c.; } 1515 \text { c.; } \\
1423 \text { cp. }\end{array}$ & скелетные $\mathrm{C}=\mathrm{C}$ & $\begin{array}{l}\text { ароматические G- и } \\
\text { S-кольца }\end{array}$ \\
\hline $1368 \mathrm{cp}$. & - & $\checkmark \mathrm{CO}$ & гваяцильные звенья + СО \\
\hline $1463 \mathrm{cp}$. & $1462 \mathrm{c}$. & $\delta \mathrm{C}-\mathrm{H}$ & $\begin{array}{l}\text { деф. асимм. С-Н в }-\mathrm{CH}_{3} \text { и } \\
-\mathrm{CH}_{2-}\end{array}$ \\
\hline 1270 оч. с. & 1328 & $\mathrm{C}=\mathrm{C}+\mathrm{vC}=\mathrm{O}$ & G и S-кольца + CO \\
\hline $1214 \mathrm{cp}$. & $1218 \mathrm{c}$. & $\mathrm{C}-\mathrm{C}+\mathrm{C}-\mathrm{O}+\mathrm{C}=\mathrm{O}$ & ароматич. кольца + CO \\
\hline $1143 \mathrm{cp}$. & 1121 оч. с. & $\delta \mathrm{C}-\mathrm{H}+\mathrm{C}-(\mathrm{OH}), \mathrm{C}-\mathrm{O}-\mathrm{C}$ & $\begin{array}{l}\text { деф. C-Н плоскостные в } \\
\text { G- и S-кольцах, спирты и } \\
\text { эфиры }\end{array}$ \\
\hline 1033 сл. & $1033 \mathrm{cp}$. & $\mathrm{C}-\mathrm{H}+\mathrm{C}-\mathrm{O}-+\mathrm{C}=\mathrm{O}$ & $\begin{array}{l}\text { ароматич. C-H S-кольца + } \\
\text { CO }\end{array}$ \\
\hline 856,816 оч. сл. & 834 оч. сл. & $\mathrm{C}-\mathrm{H}$ & $\begin{array}{l}\text { внеплоскостные } \\
\text { ароматические }\end{array}$ \\
\hline
\end{tabular}

Обозначения интенсивности п.п.: с. - сильная; оч. с. - очень сильная; ср. - средняя; сл. - слабая; оч. сл. - очень слабая.

Отсутствие полос поглощения в области 1328-1325 см-1, приписываемых колебаниям С-О-связей в сирингильных единицах, а также более выраженные пики при 1368, 1270 и 854, $816 \mathrm{~cm}^{-1}$, приписываемые валентным C-O-, деформационным плоскостным и деформационным внеплоскостным C-Н-колебаниям гвайацильных единиц, соответственно, отличают этаноллигнин пихты от этаноллигнина осины [22].

Различия в составе и структуре этаноллигнинов, выделенных из лиственной и хвойной древесины, могут обусловливать различия в их термохимических свойствах.

\section{Термогравиметрическое изучение термохимических свойств}

\section{этаноллигнинов осины и пихты в инертной среде}

Пиролитическое поведение этаноллигнинов пихты и осины в среде аргона исследовали методом неизотермического термогравиметрического (TG/ДTГ) анализа в интервале температур 30-800 ${ }^{\circ} \mathrm{C}$. Лигнин термически разлагается в широком диапазоне температур, поскольку различные функциональные группы в его структуре имеют разную термическую стабильность. В соответствии с данными термического анализа регистрируемая потеря веса обоими образцами (кривая ТГ) в интервале температур $30-220{ }^{\circ} \mathrm{C}$ составила менее 3 \% и, в основном, была связана с потерей влаги или адсорбированных газов (рис. 1).

$$
-405-
$$




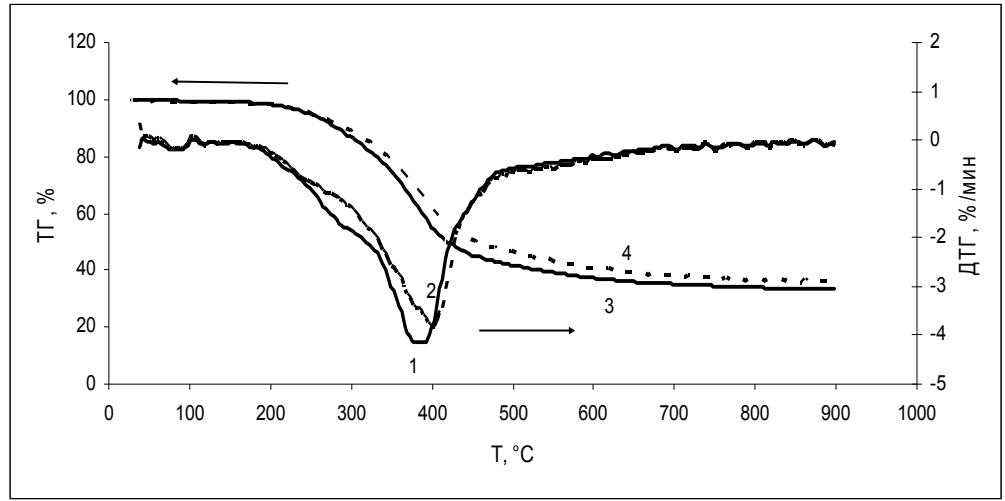

Рис. 1. Дериватограммы (ТГ/ДТГ) этаноллигнинов осины $(1,3)$ и пихты $(2,4)$, полученные при нагревании образцов в аргоне

Fig. 1. Derivatograms (TG / DTG) of ethanol lignins of aspen $(1,3)$ and fir $(2,4)$ obtained by heating the samples in argon

Температура начальной потери массы, Тн, под которой понимается 5\%-я убыль исходной массы вещества, составила для этаноллигнина осины $243{ }^{\circ} \mathrm{C}$, а для этаноллигнина пихты $252{ }^{\circ} \mathrm{C}$. Более активное терморазложение образцов лигнина начиналось при температуре немного выше $240{ }^{\circ} \mathrm{C}$ и продолжалось с примерно одинаковой скоростью до $450{ }^{\circ} \mathrm{C}$.

Существование на обоих кривых ДТГ неявного пика в виде плеча в области $250-270{ }^{\circ} \mathrm{C}$, предшествующего основной стадии пиролиза, согласно литературным данным, может соответствовать начальному разложению лигнина с выделением фенольных фракций (гваяколы, сиринголы и/или их производные) [23]. Для этаноллигнина осины присутствие «плеча» выражено более отчетливо, чем для этаноллигнина пихты, что может указывать на образование большого количества фенольных соединений.

Более существенные различия скоростей и температурных максимумов разложения наблюдаются на основной (второй) стадии терморазложения этаноллигнинов. Наибольшая скорость убыли массы $\left(-3,11 \% \cdot\right.$ мин $\left.^{-1}\right)$ для ЭЛО происходила в диапазоне температур $357-437{ }^{\circ} \mathrm{C} \mathrm{c}$ максимумом при $377,6^{\circ} \mathrm{C}$. Преимущественное разложение этаноллигнина пихты протекало в более протяженном интервале (между $337,5-437,5^{\circ} \mathrm{C}$ ) со скоростью убыли массы $-2,9 \% \cdot$ мин $^{-1}$, с максимумом при $400{ }^{\circ} \mathrm{C}$. Сдвиг максимума скорости убыли массы на основной стадии термического разложения этаноллигнина осины на $22,4{ }^{\circ} \mathrm{C}$ в сторону меньших температур по сравнению с этаноллигнином пихты коррелирует с более высоким содержанием кислорода в составе этаноллигнина осины. Как следует из данных, приведенных в табл. 2, в этом температурном интервале ЭЛО теряет около половины своей массы в виде летучих продуктов.

В диапазоне температур $350-400{ }^{\circ} \mathrm{C}$ происходит разрушение основных структурных фрагментов лигнинов (гваяцильных и сирингильных) и вторичный крекинг образовавшихся продуктов с получением соединений фенольного типа с различной молекулярной массой, выход которых возрастает с повышением температуры. Продукты пиролиза на данной стадии разложения лигнинов представляют собой сложную смесь органических соединений, которые содержат в своем составе ароматические кольца, гидроксильные и алкильные группы и отражают особенности состава и структуры исходного лигнина [10, 24, 25]. 
Таблица 2. Основные характеристики процесса терморазложения этаноллигнинов в аргоне

Table 2. The main characteristics of thermal decomposition process of ethanollignins in argon

\begin{tabular}{|c|c|c|c|}
\hline \multirow{2}{*}{ Образец } & \multicolumn{3}{|c|}{$\begin{array}{c}\text { Температурный интервал, }{ }^{\circ} \mathrm{C} / \text { скорость убыли массы, \% } \times \text { мин }^{-1} \\
\text { Потеря массы в интервале температур, \% отн. }\end{array}$} \\
\hline \multirow{2}{*}{ ЭЛО } & $\frac{(30-243) / 0,25}{5,01}$ & $\frac{(243-450) / 2,40}{49,72}$ & $\frac{(450-600) / 0,53}{8,05}$ \\
\hline \multirow{2}{*}{ ЭЛП } & $\frac{(30-252) / 0,24}{5,03}$ & $\frac{(252-450) / 2,22}{44,50}$ & $\frac{(450-600) / 0,62}{9,40}$ \\
\hline
\end{tabular}

При термодеструкции лигнина протекают конкурирующие реакции деполимеризации с образованием ароматических продуктов с более низкой молекулярной массы, реакции сшивки ароматических соединений и их карбонизация $[9,10]$.

В интервале температур $450-600{ }^{\circ} \mathrm{C}$ (третья стадия) деструкции этаноллигнинов наблюдается значительное снижение скорости убыли массы, и терморазложение, в основном, завершается к $600{ }^{\circ} \mathrm{C}$ с образованием углеродных остатков массой $37,13 \%$ для лигнина осины и 40,93 \% для лигнина пихты. Вероятно, при этом происходит распад части ароматических колец в лигнине и их конденсация в графитоподобные структуры $[10,26]$.

Выход углеродных продуктов постепенно снижается с повышением температуры до $700{ }^{\circ} \mathrm{C}$ и далее остается почти постоянным. При температуре $800{ }^{\circ} \mathrm{C}$ происходит дополнительное высвобождение летучих фракций с образованием углеродного остатка с выходом 33,9 \% из этаноллигнина осины и 36,9 \% из лигнина пихты. Более высокий выход продуктов в случае этаноллигнина пихты согласуется с более высокой склонностью гваяцилпропановых единиц к реакциям конденсации $[25,27]$.

Изучение термодеструкиии этаноллигнинов осины и пихты

в инертной атмосфере методами ИКС и СЭМ

Для более детального изучения структурных изменений этаноллигнинов на основных этапах их терморазложения изучены ИК-спектры образцов лигнинов после их выдержки при определенных температурах. Сопоставление спектров лигнинов до и после их выдержки при температуре $200{ }^{\circ} \mathrm{C}$ не выявило заметных отличий в составе функциональных групп.

Сравнение ИК-спектров образца этаноллигнина осины до и после термообработки при $240{ }^{\circ} \mathrm{C}$ (ЭЛО-240) указывает на незначительное снижение в термообработанном лигнине интенсивности п.п. в области колебаний алифатических C-Н-групп (2934-2839 см-1). Одновременное уменьшение интенсивности поглощения сложноэфирных связей при $1116 \mathrm{~cm}^{-1}$, вероятно, свидетельствует о том, что алкилэфирные мостики в сирингильных фрагментах лигнина первыми начинают подвергаться термическому разложению.

Более значительные изменения наблюдаются в ИК-спектре пиролизованного при $380{ }^{\circ} \mathrm{C}$ лигнина осины (ЭЛО-380) (рис. 2, кривая 2).

В спектре этого образца наблюдается существенное уменьшение интенсивностей п.п. -C-O-H-, C-H-, C-O- групп и C-C- связей, что свидетельствует о снижении содержания органических соединений в пиролизованном лигнине. Наблюдаемый сдвиг основных полос поглощения в область более низких длин волн (на 7-10 см-1), вероятно, обусловлен появлени- 


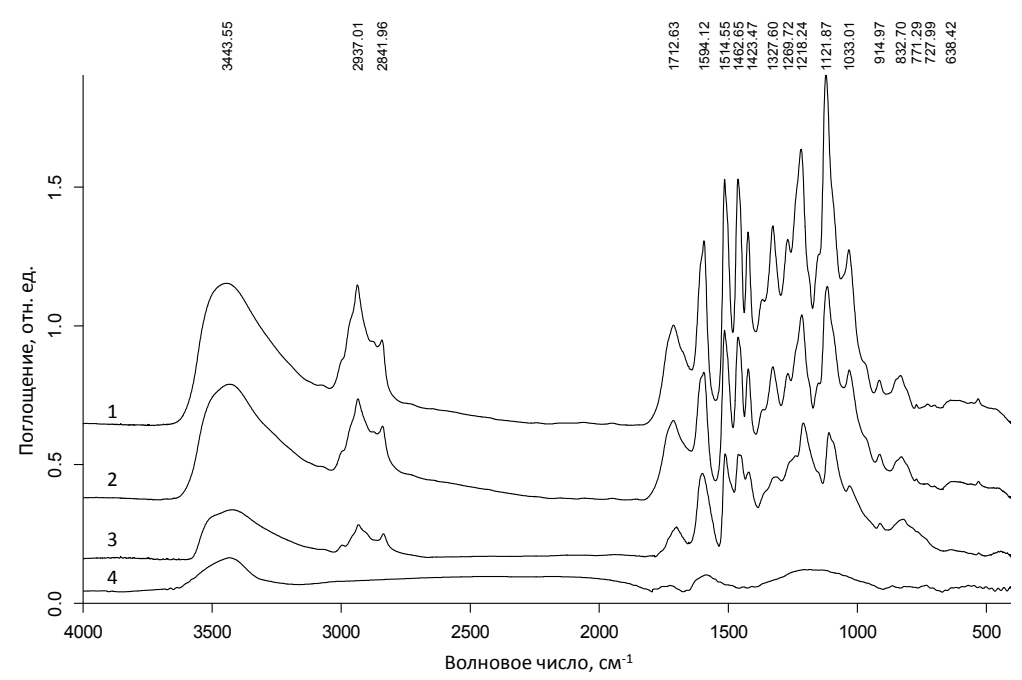

Рис. 2. ИК-спектры этаноллигнина осины: кривая 1 - исходный; кривая 2 - ЭЛО-240; кривая 3 - ЭЛО-380; кривая 4 - ЭЛО-600

Fig. 2. IR spectra of aspen ethanol lignin: curve 1 - initial; curve 2 - ELA-240; curve 3 - ELA-380; curve 4 ELA-600

ем ароматических структур, включенных в систему сопряжения с непредельными связями, в том числе с $\mathrm{C}=\mathrm{O}$ группами. Общий вид спектра подтверждает, что полученные продукты сохраняют ароматическую структуру, характерную для лигнина $\mathrm{S}+\mathrm{G}-$ типа [28, 29]. Возможными продуктами превращения сирингильных и гваяцильных фрагментов лигнина являются производные фенольного типа - наиболее характерные продукты пиролиза лигнина $[8,10]$.

Изучение методом сканирующей электронной микроскопии (СЭМ) морфологии образцов этаноллигнинов после термообработки показало, что при температуре, не превышающей $200{ }^{\circ} \mathrm{C}$, в них происходят только физические изменения, обусловленные размягчением и плавлением лигнина. При этом шероховатые поверхности отдельных частиц исходного лигнина превращались в единую пластичную массу с образованием полостей микронного размера, через которые, вероятно, осуществлялось выделение газообразных веществ.

Повышение температуры до $240{ }^{\circ} \mathrm{C}$ приводит к изменениям в структуре этаноллигнина осины, на что указывает появление на его поверхности обогащенных углеродом частиц (отмечено кружком на рис. $3 a$ ).

Образование углеродных частиц также подтверждено результатами химического анализа. Количество образующегося углерода возрастает с температурой пиролиза. При температурах 350-400 ${ }^{\circ} \mathrm{C}$ углерод покрывает всю поверхность образцов, придавая ей черный цвет и блеск. При этом происходит формирование плотного однородного материала с зародышевой структурой мелких пор в обуглероженной матрице.

Изучение методом СЭМ морфологических особенностей поверхности пиролизованных при $600^{\circ} \mathrm{C}$ образцов этаноллигнинов показало, что в образующихся углеродных остатках присутствуют множественные дефекты, трещины и крупные поры, что сопровождается микрорасслаиванием образцов и некоторым увеличением их поверхности. 


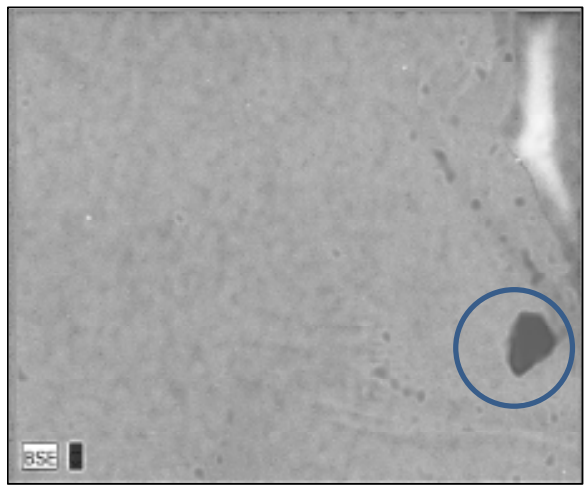

а) ЭЛО-240

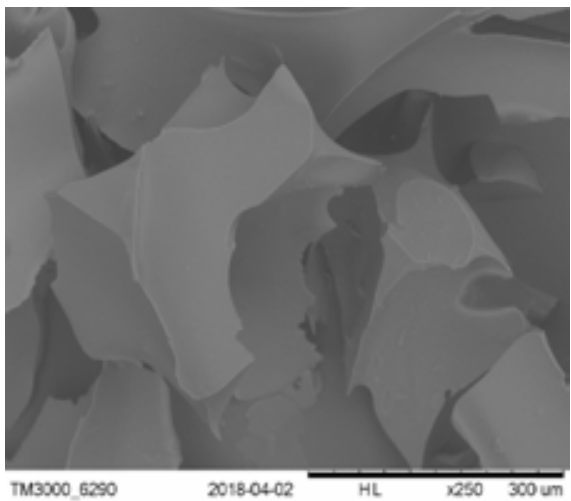

б) ЭЛП-400

Рис. 3. СЭМ-изображения образцов этаноллигнина осины после термообработки при $240{ }^{\circ} \mathrm{C}$ (a) и этаноллигнина пихты после термообработки при $400{ }^{\circ} \mathrm{C}$ (б). Увеличение 250 раз

Fig. 3. SEM images of samples of aspen ethanol lignin after heat treatment at $240{ }^{\circ} \mathrm{C}$ (a) and fir ethanol lignin after heat treatment at $400{ }^{\circ} \mathrm{C}$ (b). Magnification 250 times

\section{Термогравиметрическое изучение термохимических свойств древесины осины}

и ее компонентов в инертной атмосфере

Проведено сравнение термохимических свойств древесины осины и выделенных из нее основных компонентов - микрокристаллической целлюлозы и этаноллигнина. Химический состав древесины осины (ДО) включал (\%, мас): целлюлоза - 49,9; гемицеллюлозы - 24; лигнин - 19,4; экстрактивные - 4,3; зольность - 0,37. Микрокристаллическая целлюлоза, полученная по методике [29], содержала в своем составе менее 2 \% масс. лигнина.

Кривые потери массы вещества в ходе процесса термической деструкции исследованных образцов исходной древесины осины, этаноллигнина и МКЦ в атмосфере аргона приведены на рис. 4.

Микрокристаллическая целлюлоза разлагается с потерей массы 67,9 \% в узком температурном диапазоне - от 262 до $357^{\circ} \mathrm{C}$. Максимальная убыль массы (-7,22 \%/мин) соответствует температуре $333,7^{\circ} \mathrm{C}$. Высокая симметричность и резкость пика обусловлена высокой степенью упорядоченности структуры МКЦ. Пиролиз образца МКЦ завершается при температуре $800^{\circ} \mathrm{C}$ с образованием углеродного остатка в количестве 13,7 мас. \%.

Терморазложение древесины осины начинается при температуре $236^{\circ} \mathrm{C}$, при достижении которой образец теряет около 3 \% своей массы. В интервале температур $236-320{ }^{\circ} \mathrm{C}$ на кривой ДТГ появляется отчетливый пик в виде плеча при $318{ }^{\circ} \mathrm{C}$, который обычно связывают с разложением гемицеллюлоз [3]. При этом скорость убыли массы вещества составляет около $-2,38 \%$ /мин, а общая потеря массы - 21,51 \%.

В температурном интервале $320-380^{\circ} \mathrm{C}$ преимущественно происходит разложение целлюлозы. Максимальная скорость убыли массы (-7,15 \% /мин) соответствует температуре $363,4{ }^{\circ} \mathrm{C}$. Потеря массы в этом температурном интервале составляет 46,96 \%. Совокупная убыль вещества при нагреве до $380^{\circ} \mathrm{C}$ достигает $71,4 \%$. В этом интервале температур также подвергается терморазложению значительная часть лигнина в составе древесины.

$$
-409-
$$




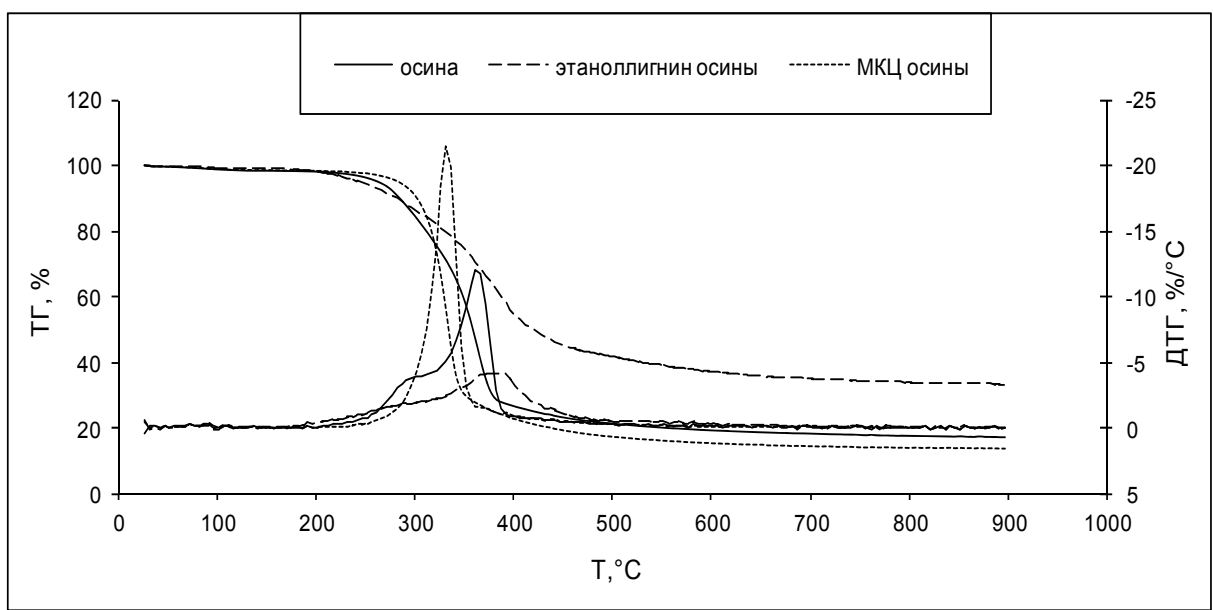

Рис. 4. Дериватограммы (ТГ/ДТГ) образцов древесины осины, МКЦ из древесины осины и этаноллигнина из древесины осины, полученные при нагревании образцов в аргоне

Fig. 4. Derivatograms (TG/DTG) of aspen wood, MCC from aspen wood and ethanol lignin from aspen, obtained by heating of the samples in argon

Таблица 3. Результаты термогравиметрического изучения (ТГ/ДТГ) терморазложения образцов древесины осины, целлюлозы и этаноллигнина в аргоне

Table 3. The results of thermogravimetric study (TG/DTG) of the thermal decomposition of aspen wood, cellulose and ethanollignin in argon

\begin{tabular}{|c|c|c|c|c|c|}
\hline \multicolumn{6}{|c|}{ Древесина осины } \\
\hline $\begin{array}{c}\text { № } \\
\text { стадии }\end{array}$ & Диапазон T, ${ }^{\circ} \mathrm{C}$ & $\mathrm{T}_{\max },{ }^{\circ} \mathrm{C}$ & $\begin{array}{c}\text { Убыль } \\
\text { массы, \% }\end{array}$ & $\begin{array}{c}\text { Скорость } \\
\text { убыли массы } \\
\text { (ДТГ), \%/мин }\end{array}$ & $\begin{array}{c}\text { Остаточная } \\
\text { масса, } \%\end{array}$ \\
\hline I & $30-236$ & 60,0 & 2,90 & $-0,15$ & 97,10 \\
\hline II & $\begin{array}{l}236-320 \\
320-380\end{array}$ & $\begin{array}{l}318,3 \\
363,4\end{array}$ & $\begin{array}{l}21,51 \\
46,96\end{array}$ & $\begin{array}{l}-2,38 \\
-7,15\end{array}$ & $\begin{array}{l}75,60 \\
28,64\end{array}$ \\
\hline III & $380-600$ & 440,0 & 9,67 & $-0,44$ & 18,97 \\
\hline \multicolumn{6}{|c|}{ Микрокристаллическая целлюлоза осины } \\
\hline I & $30-262$ & - & 2,95 & $-0,13$ & 97,05 \\
\hline II & $262-357$ & 333,7 & 68,61 & $-7,22$ & 28,44 \\
\hline III & $357-600$ & - & 13,32 & $-0,54$ & 15,12 \\
\hline \multicolumn{6}{|c|}{ Этаноллигнин осины } \\
\hline I & $30-225$ & - & $\sim 3,0$ & $-0,16$ & 97,0 \\
\hline II & $225-437$ & 376,3 & 49,81 & $-2,3$ & 47,11 \\
\hline III & $437-600$ & - & 9,98 & $-0,6$ & 37,13 \\
\hline
\end{tabular}

При дальнейшем нагреве до 600 $\mathrm{C}$ древесина пиролизуется до углеродного остатка массой 18,9 \%. Отметим, что в этих условиях масса углеродного остатка из этаноллигнина составляет около $37,13 \%$.

Терморазложение этаноллигнина происходит в аналогичном температурном диапазоне, что и древесина осины, из которой он был выделен (табл. 3). Поскольку интервалы термиче- 
ской деструкции компонентов древесины частично перекрываются, то трудно установить их точные границы $[3,16]$.

При повышении температуры пиролиза древесины от 600 до $800{ }^{\circ} \mathrm{C}$ убыль ее массы составляет всего $\sim 1,6 \%$ отн.

Температуры, обеспечивающие наибольшие скорости разложения древесины осины, целлюлозы и лигнина, составляли $363,4,333,7$ и $377,6^{\circ} \mathrm{C}$ соответственно. Поскольку максимальная скорость разложения лигнина ниже, чем для древесины, из которой он был выделен, то и профиль разложения этаноллигнина осины сдвигается в область более высоких температур по сравнению с ДО и МКЦ (рис. 4).

Таким образом, лигнин, вследствие его поперечно-связанной ароматической структуры, является более устойчивым к термической деградации по сравнению с целлюлозой и древесиной и разлагается в более продолжительном интервале температур. Полученные данные находятся в хорошем соответствии с приведенными в литературе $[6,7,17]$.

Термогравиметрическое изучение термохимических свойств этаноллигнинов осины

и пихты в среде воздуха

При нагревании образцов этаноллигнинов в среде воздуха в интервале температур 30$158{ }^{\circ} \mathrm{C}$ преимущественно устраняется влага. При этом убыль массы равна 1,25-1,36 \% (рис. 5). Температура начального разложения составила для этаноллигнина осины $242{ }^{\circ} \mathrm{C}$, а для этаноллигнина пихты $-255^{\circ} \mathrm{C}$ (рис. 5). Возможно, к этому моменту лигнины теряли не только адсорбированную, но и связанную воду, а также частично и легколетучие компоненты за счет разрушения алкильной боковой цепи [24].

На второй стадии термической деструкции (предшествующей стадии горения) происходит основной процесс деградации этаноллигнинов с наиболее важными изменениями в составе продуктов превращения. При этом терморазложение этаноллигнина осины наступает немного раньше, чем этаноллигнина пихты. На кривой ДТГ этаноллигнина осины на-

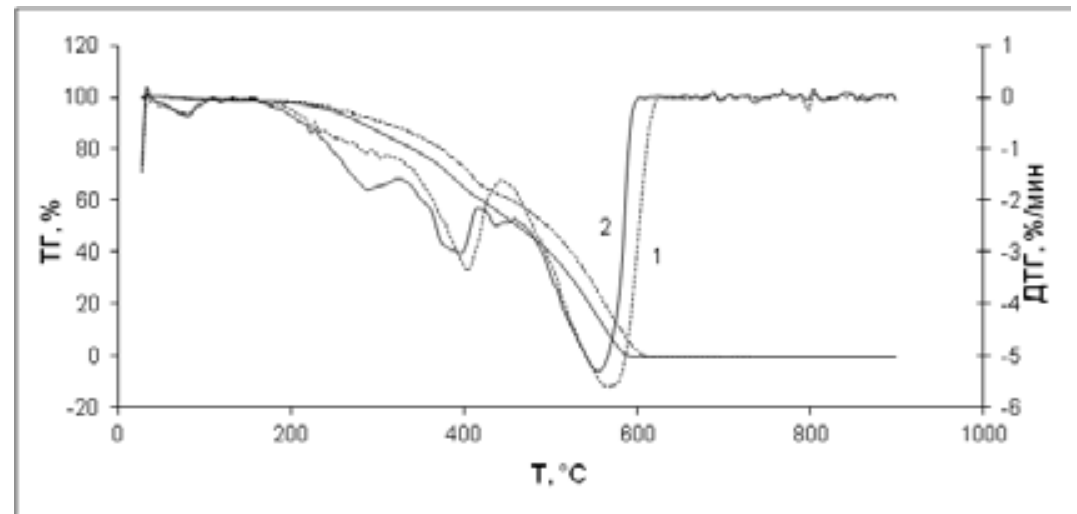

Рис. 5. Дериватограммы (ТГ/ДТГ) этаноллигнина пихты (1) и этаноллигнина осины, полученные при нагревании образцов на воздухе

Fig. 5. Derivatograms (TG/DTG) of ethanol lignin from abies wood (1) and ethanol lignin from aspen wood obtained by heating of the samples in air 
блюдаются два отдельных пика между 242 и $417^{\circ} \mathrm{C}$. Первый, небольшой пик находится в интервале $242-327{ }^{\circ} \mathrm{C}$, и максимальная скорость распада соответствует температуре $295^{\circ} \mathrm{C}$. Второй, более интенсивный пик сдвинут в область более высоких температур, с максимальной скоростью убыли массы $\left(-2,56 \% \cdot\right.$ мин $\left.^{-1}\right)$ при $396^{\circ} \mathrm{C}$. Суммарная потеря массы вещества на второй стадии термической деструкции составила 34,46 \%. С учетом литературных данных можно предположить, что первый пик на кривой ДТГ этаноллигнина осины соответствует первичному пиролизу с образованием соединений гваякольного и сирингольного типов [10, 23], а второй пик обусловлен крекингом первичных продуктов распада с образованием замещенных фенолов [24, 30].

Для этаноллигнина пихты, начиная с температуры $255^{\circ} \mathrm{C}$, характерно более плавное, без экстремумов, уменьшение массы со скоростью около $-1 \% \cdot$ мин $^{-1}$ вплоть до температуры $312{ }^{\circ} \mathrm{C}$. При дальнейшем повышении температуры скорость разложения возрастает до $-2,25 \% \cdot$ мин $^{-1}$. На кривой ДТГ этого образца в температурном диапазоне $312-444{ }^{\circ} \mathrm{C}$ наблюдается пик при $402{ }^{\circ} \mathrm{C}$, который соответствует максимальной скорости потери вещества. Общая потеря массы составляет 33,16 \%. Основные характеристики термического разложения этаноллигнинов пихты и осины на воздухе приведены в табл. 4.

Дальнейшее нагревание этаноллигнинов (третья стадия) свыше температуры $417^{\circ} \mathrm{C}$ (для образца ЭЛО) и свыше $444{ }^{\circ} \mathrm{C}$ (для образца ЭЛП) приводит к завершению процесса термодеструкции лигнинов и к увеличению скорости убыли массы за счет сгорания образовавшегося углеродного остатка. Судя по ТГ кривым, образец ЭЛО имеет более низкую температуру начала горения, чем образец ЭЛП, причем сам процесс горения протекает более интенсивно. Наибольшая скорость потери массы на заключительной стадии термической деструкции в среде воздуха соответствует температуре $555{ }^{\circ} \mathrm{C}$ для лигнина осины и $585,2{ }^{\circ} \mathrm{C}$ для лигнина пихты. На финальных стадиях распада, когда идут процессы возгорания, скорости деструкции для обоих типов лигнинов увеличиваются, достигая примерно одинаковых значений $\left(-3,48 \% \cdot\right.$ мин $^{-1}$ для ЭЛО и $-3,44 \% \cdot$ мин $^{-1}$ для лигнина пихты). Для образца ЭЛО окончание термодеструкции наступает раньше, чем для образца ЭЛП $\left(605^{\circ} \mathrm{C}\right.$ и $627^{\circ} \mathrm{C}$ соответственно).

Следует отметить, что во всех температурных интервалах разложение лигнина осины проходило с более высокими скоростями убыли массы, чем лигнина пихты. Из анализа литературных сведений известно, что эфирные связи между сирингильными звеньями расщепляются легче, чем между гваяцильными $[24,25]$. Таким образом можно заключить, что лигнин пихты

Таблица 4. Результаты термогравиметрического изучения (ТГ/ДТГ) терморазложения этаноллигнинов осины и пихты в среде воздуха

Table 4. The results of the thermogravimetric study (TG/DTG) of the thermal decomposition of ethanollignins of aspen wood and fir wood in air

\begin{tabular}{|c|c|c|c|c|}
\hline \multirow{2}{*}{ Образец } & \multicolumn{4}{|c|}{ Температурный интервал, ${ }^{\circ} \mathrm{C} /$ скорость убыли массы, \% отн. $\times$ мин $^{-1}$} \\
Потеря массы в интервале температур, \% отн
\end{tabular}


(G-лигнин) более термически стабилен, чем лигнин из осины (SG-лигнин), из-за более высокой термической стабильности гваяцильных звеньев.

Проведенные расчеты величин теплоты сгорания образцов показали, что они имеют близкие значения и составили 10799 Дж/г для этанолигнина осины и 11050 Дж/г для этаноллигнина пихты.

\section{Сравнение термохимических свойств этаноллигнинов осины и пихты}

в среде аргона и воздуха

В результате выполненных исследований установлено, что пиролиз этаноллигнинов в среде воздуха протекает в более протяженном температурном диапазоне, чем в инертной среде. Основные характеристики термодеструкции образцов этаноллигнина в этих средах приведены в табл. 5. Начальные температуры разложения, когда образец теряет около 5 \% своей массы, практически совпадают для обоих типов этаноллигнинов в среде воздуха и аргона $\left(242{ }^{\circ} \mathrm{C}-\right.$ для ЭЛО и $\sim 252-255^{\circ} \mathrm{C}$ - для ЭЛП), а кривые деструкции имеют сходные профили скоростей потери массы в интервале температур от комнатной до $\sim 250^{\circ} \mathrm{C}$. Это свидетельствует о сходном протекании термической деструкции этаноллигнинов в среде как аргона, так и воздуха в этом интервале температур.

Для этаноллигнина осины интервал температур двух основных стадий разложения вещества, на которых достигается принятая в литературе в качестве тестовой 50 \% -ная потеря массы, составляет в среде воздуха $242-462{ }^{\circ} \mathrm{C}$, и средняя скорость убыли массы равна $-2,05 \% \cdot$ мин $^{-1}$. В среде аргоне $50 \%$-ная убыль массы происходит в более узком интервале - между 242 и $\sim 225{ }^{\circ} \mathrm{C}$ с несколько более высокой скоростью убыли массы $\left(-2,64 \% \cdot\right.$ мин $\left.^{-1}\right)$.

В случае этаноллигнина пихты разложение его на воздухе с $50 \%$-ной убылью вещества идет в более протяженном температурном интервале - от 255 до $495{ }^{\circ} \mathrm{C}$ со средней скоростью расходования массы $-1,88 \% \cdot$ мин $^{-1}$, чем в инертной атмосфере (интервал $252-455^{\circ} \mathrm{C}$ и скорость потери массы $-2,17 \% \cdot$ мин $\left.^{-1}\right)$.

Возможной причиной более медленного тероморазложения образцов таноллигнина в окислительной среде по сравнению с инертной может являться образование более стабильных промежуточных соединений. Это может происходить за счет окисления концевых групп, типа альдегидных или спиртовых, до более устойчивых карбоксильных групп либо вследствие

Таблица 5. Сравнение параметров терморазложения этаноллигнинов осины и пихты в среде воздуха и аргона

Table 5. Comparison of the thermal decomposition parameters of ethanollignins of aspen wood and fir wood in air and argon

\begin{tabular}{|c|c|c|c|c|c|}
\hline Образец & $\begin{array}{c}\text { Основной } \\
\text { диапазон } \\
\text { убыли массы }\end{array}$ & ДТГ макс & $\begin{array}{c}\text { Убыль массы в } \\
\text { интервале, \% }\end{array}$ & дТГ, \% мин $^{-1}$ & $\begin{array}{c}\text { Суммарная } \\
\text { убыль } \\
\text { вещества, \% }\end{array}$ \\
\hline ЭЛО, воздух & $242-462$ & 396 & 45,15 & $-2,05$ & 49,92 \\
\hline ЭЛО, аргон & $242-425$ & 377,6 & 45,33 & $-2,64$ & 49,98 \\
\hline ЭЛП, воздух & $252-495$ & 402 & 45,25 & $-1,90$ & 50,01 \\
\hline ЭЛП, аргон & $242-455$ & 400 & 44,6 & $-2,17$ & 49,96 \\
\hline
\end{tabular}


декарбонилирования алкильных боковых цепочек, имеющих концевые альдегидные группы. Происходящая в интервале температур $240-250{ }^{\circ} \mathrm{C}$ окислительная термостабилизация, очевидно, связана с образованием кислородсодержащих функциональных групп в структуре лигнина. Процессы дегидратации и окисления, а также образование и элиминирование карбонильных групп во время термостабилизации, вероятно, протекают параллельно с деструкцией алифатических звеньев.

Более детальное объяснение наблюдаемых отличий в термохимических свойствах хвойных и лиственных лигнинов в инертной и окислительной среде станет возможным в результате дополнительных исследований, позволяющих оценить весь комплекс выделяющихся газообразных веществ (летучих и конденсируемых), жидких веществ (смолы, масла) и твердых продуктов разложения.

\section{Заключение}

Изучена взаимосвязь между интенсивностью потери массы и степенью термического разложения этаноллигнинов пихты и осины в инертной (аргон) и окислительной (воздух) средах. Установлено, что в инертной среде максимум скорости убыли массы на основной стадии термического разложения этаноллигнина осины сдвинут на $22,4{ }^{\circ} \mathrm{C}$ в сторону меньших температур по сравнению с этаноллигнином пихты. Это свидетельствует о меньшей термической устойчивости сирингильных структур лиственного лигнина по сравнению с гваяцильными структурами хвойного лигнина.

Методом ИК-Фурье-спектроскопии установлено последовательное снижение содержания алифатических, алкил-эфирных и спиртовых группировок при карбонизации лигнинов в атмосфере аргона, начиная с температуры $240{ }^{\circ} \mathrm{C}$. Продукты термического разложения лигнинов при температуре $380-400{ }^{\circ} \mathrm{C}$ сохраняют структуру и характер замещения ароматического кольца, присущего исходным лигнинам.

Обнаружено образование на поверхности этанолигнинов углеродных частиц при температурах терморазложения около $600{ }^{\circ} \mathrm{C}$. Вследствие большей термической устойчивости гваяцильных структур этаноллигнина пихты выход углеродного остатка при его терморазложении при $800{ }^{\circ} \mathrm{C}(36,9 \%)$ выше, чем углеродного остатка из лигнина осины (33,9 \%).

При изучении методом СЭМ морфологии поверхности образцов лигнинов на основных этапах термического разложения обнаружено появление дефектных полостей в структуре материала, начиная с температуры $240{ }^{\circ} \mathrm{C}$, и усиление процесса его карбонизации по мере повышения температуры пиролиза до $600{ }^{\circ} \mathrm{C}$.

Сопоставление термохимических свойств в среде аргона древесины осины и выделенных из нее МКЦ и этаноллигнина позволило установить температуры, соответствующие максимальным скоростям их термораспада. Показано, что этаноллигнин является более термически устойчивым $\left(377,6^{\circ} \mathrm{C}\right)$ по сравнению с древесиной $\left(363,4{ }^{\circ} \mathrm{C}\right)$ и МКЦ $\left(333,7^{\circ} \mathrm{C}\right)$. Обнаружено, что основные стадии преимущественного разложения вещества, сопровождающиеся 50\%-ной убылью массы, для обоих изученных видов этаноллигнина в атмосфере воздуха более протяженные, чем в аргоне, что, возможно, связано с формированием в окислительной среде более стабильных фрагментов разложения на первичной стадии пиролиза. 
Количественно оценен суммарный тепловой эффект термоокислительного разложения лиственного и хвойного лигнинов в среде воздуха - для этаноллигнина осины он составил 10799 Дж/г, а для этаноллигнина пихты - 11050 Дж/г.

\section{Благодарности}

Исследования выполнены при частичной финансовой поддержке РФФИ (проект № 18-5316001) в рамках Международного научного объединения «Биомасса» между Францией и Россией и базового проекта № 0356-2016-0505 (V.46.4.2) Программы фундаментальных научных исследований государственных академий наук на 2013-2020 годы.

\section{Список литературы}

1. Isahak W.N.R.W., Hisham M.W.M., Yarmo M.A., Yun Hin T.-Y. A review on bio-oil production from biomass by using pyrolysis method. Renew. Sustain. Energy Rev. 2012. Vol. 16, P. 5910-5923.

2. Zakzeski J., Bruijnincx P.C.A., Jongerius A.L., Weckhuysen B.M. The catalytic valorization of lignin for the productionof renewable chemicals. Chem. Rev. 2010, P. 3552-3599.

3. Poletto M., Zattera A.J., Forte M.M.C., Santana R.M.C. Thermal decomposition of wood: Influence of wood components and cellulose crystallite size. Bioresource Technology 2012. Vol. 109, P. 148-153.

4. Кузнецов Б.Н., Чесноков Н.В., Яценкова О.В., Шарыпов В.И. Новые гетерогеннокаталитические методы конверсии лигноцеллюлозной биомассы в химические продукты. Известия Академии наук. Серия химическая 2013. Т. 62(7), C.1493-1503. [Kuznetsov B.N., Chesnokov N.V., Yatsenkova O.V., Sharypov V.I. New methods of heterogeneous catalysis for lignocellulosic biomass conversion to chemicals. Russian Chemical Bulletin, International Edition 2013. Vol. 62(7), P. 1493-1502. (In Russ)].

5. Tejado A., Pena C., Labidi J., Echeverria J.M., Mondragon I. Physico-chemical characterization of lignins from different sources for use in phenol-formaldehyde resin synthesis. Bioresource Technology 2007. Vol. 98, P. 1655-1663.

6. Bonelli P.R., Cukierman A.L. Physico-chemical Characteristics and Pyrolysis Behavior of Klason Lignins Isolated from Agroindustrial Biomass. Energy Sources, Part A: Recovery, Utilization, and Environmental Effects 2015. Vol. 37, P. 1534-1541.

7. Wang S., Wang K., Liu Q., Gu Yu, Luo Z., Cen K.F. Comparison of the pyrolysis behavior of lignins from different tree species Fransson. Biotechnology Advances 2009. Vol. 27(5), P. 562-567.

8. Asmadi M., Kawamoto H., Saka S. Thermal reactions of guaicol and syringol as lignin model aromatic nuclei. J. Anal. Appl. Pyrol. 2011. Vol. 92, P. 88-98.

9. Nakamura T., Kawamoto H., Saka S. Condensation reactions of some lignin related compounds at relatively low pyrolysis temperature. Journal of Wood Chemistry and Technology 2007. Vol. 27, P. 121-133.

10. Shen D.K., Gu S., Luo K.H., Wang S.R., Fang M.X. The pyrolytic degradation of woodderived lignin from pulping process. Bioresource Technology 2010. Vol. 101, P. 6136-6146.

11. Nassar M.M. and G. D. M. MacKay Mechanism of thermal decomposition of lignin. Wood and Fiber Science 1984. Vol. 16(3), P. 441-453. 
12. Buranov A.U., Ross, K.A., Mazza G. Isolation and characterization of lignins extracted from flax shaves using pressurized aqueous ethanol. Bioresource Technology 2010. Vol. 101, P. 74467455 .

13. Quesada-Medina J., Lopez-Cremades F.J., Olivares-Carrillo P. Organosolv extraction of lignin from hydrolyzed almond shells and application of the d-value theory. Bioresource Technology 2010. Vol. 101, P. 8252-8260.

14. Weinwurm F., Drljo A., Silva T.L.S., Friedl A. Principles of ethanol organosolv lignin precipitation: process simulation and energy demand. Chemical Engineering Transactions 2014. Vol. 39, P. 583-588.

15. El-Mansuori N.-E., Salvado J. Structural characterization of technical lignin for the production of adhesives: application to lignosulfonate, kraft, soda-antraquinone, organosolv and ethanol process lignins. Ind. Crop. Prod. 2006. Vol. 24, P. 8-16.

16. Sebio-Punal T., Naya S., Lopez-Beceiro J., Tarrio-Saaverda J., Artiaga R. Thermo-gravimetric analysis of wood, holocellulose, and lignin from five wood species. J. Therm. Anal. Calorim. 2012. Vol. 109(3), P. 1163-1167.

17. Poletto M., Oliet D.J.C., Alonso M., Gilarranz M.V., Rodríguez M.A.F. Thermal stability and pyrolysis kinetics of organosolv lignins obtained from Eucalyptus globules. Industrial Crops \& Products 2008. Vol. 27, P. 150-156.

18. Ningbo Gao, Aimin Li, Cui Quan, Lin Du, Yue Duan. TG-FTIR and [Py-GC/MS] analysis on pyrolysis and combustion of pine sawdust. J. Anal. Appl. Pyrol. 2013. Vol. 100, P. 26-32.

19. Судакова И.Г, Кузнецов Б.Н., Гарынцева Н. В., Королькова И.В. Состав и связующие свойства лигнинов, полученных окислительной делигнификацией древесины пихты, осины и березы в среде уксусной кислоты. Химия растительного сырья. 2010(3), С. 5560. [Sudakova I.G., Kuznetsov B.N., Garyntseva N.V., Korolkova I.V. Composition and binding properties of lignins obtained by oxidative delignification of fir, aspen and birch wood in acetic acid. Chemistry of plant raw materials 2010. Vol. 3, P. 55-60. (In Russ)].

20. Физическая химия лигнина; под ред. К.Г. Боголицына и В.В. Лунина. ИздвоАрхангельского государственного технического университета. Архангельск, 2009. [Physical chemistry of lignin; Bogolitsyn K.G, Lunin V.V., Eds.; Arkhangelskstate technical university. Arkhangelsk, 2009 (In Russ.)].

21. Faix O. In Methods in Lignin Chemistry; Lin S.Y., Dence C.W., Eds.; Springer-Verlag: Berlin. 1992. P. 83-109.

22. Lupon J.S., Singh S., Parthasarathi R., Simmons B.A., Henry R.J. Recent innovation in analytical methods for the qualitative and quantitative assessment of lignin. Renewable and Susutainable Energy Reviews 2015. Vol. 49, P. 871-906.

23. Liu Q., Wang S.R., Zhen Y., Luo Z.Y., Cen K.F. Mechanism study of wood lignin pyrolysis by using TG-FTIR analysis. J. Anal. Appl. Pyrol. 2008. Vol. 82, P. 170-177.

24. Brebu M. and Vasile C. Thermal degradation of lignin - a review. Cellulose Chem. Technol. 2010. Vol. 44 (9), P. 353-363.

25. Poletto M. Assessment of the thermal behavior of lignins from softwood and hard-wood species. Maderas. Ciencia y tecnología 2017. Vol. 19(1), P. 63-74. 
26. Masashi Kijima, Takaharu Hirukawa, Fuminori Hanawa, Toshimitsu Hata. Thermal conversion of alkaline lignin and its structured derivatives to porous carbonized materials. Bioresource Technology 2011. Vol. 102, P. 6279-6285.

27. Faix O., Jakab E., Till F., Szekely T. Study on low mass thermal degradation products of milledwood lignins by thermogravimetry-mass-spectrometry. Wood Sci Technol. 1988. Vol. 22, P. 131137.

28. Pandey K.K. A study of Chemical Structure of Soft and Hardwood and Wood Polymers by FTIR Spectroscopy. J. Applied Polymers Science 1999. Vol. 71, P. 1969-1975.

29. Кузнецов Б.Н., Судакова И.Г., Яценкова О.В., Гарынцева Н.В., Ратабоул Ф., Дьякович Л. Оптимизация одностадийных процессов получения микрокристаллической целлюлозы пероксидной делигнификацией древесины в присутствии катализатора $\mathrm{TiO}_{2}$. Kamaлиз в промышленности 2018. № 3, С. 80-88. [Kuznetsov B.N., Sudakova I.G., Yatsenkova O.V., Garyntseva N.V., Rataboul F., Djakovitch L. Optimization of single-stage processes of microcrystalline cellulose production by peroxide delignification of wood in the presence of catalyst. Catalysis in industry 2018. N 3, P. 80-88. (in Russ.)].

30. Шарыпов В.И., Береговцова Н.Г., Барышников С.В., Мирошникова А.В., Кузнецов Б.Н. Изучение состава и термических превращений этаноллигнина, выделенного из древесины осины. Журнал СФУ. Химия 2016. Т. 9(3), С. 296-307. [Sharypov V.I., Beregovtsova N.G., Baryshnikov S.V., Miroshnikova A.V., Kuznetsov B.N. Study of the composition and thermal transformations of ethanollignin isolated from the aspen wood. J. Sib. Fed. Univ. Chem. 2016. Vol. 9(3), P. 296-307. (In Russ.)]. 